\title{
Analysis and assessment of economic state of enterprise in context of strategy of import substitution
}

\author{
Beregova Galina Mihaylovna \\ Institute of Economics, management and law \\ Irkutsk National Research Technical University \\ Irkutsk, Russian Federation \\ gmberegova@mail.ru
}

\author{
Klipin Alexey Olegovich \\ Institute of Economics, management and law \\ Irkutsk National Research Technical University \\ Irkutsk, Russian Federation \\ alek7ey09@gmail.com
}

\begin{abstract}
The article analyses the concept of import substitution in a complex geopolitical situation in the world. It identifies and reveals the problems with establishing a fund for industrial development and its vulnerability to market conditions. For various example, it reveals the rapid development of import-substituting strategies in domestic enterprises. The possibility and expediency are considered as the replacement of certain groups of imported products in the domestic market, particularly production of the construction materials. The conclusion is that the policy of import substitution as a phenomenon can be successfully analyzed and applied to the examples of other countries.
\end{abstract}

Keywords - import of substitution, industrial development, economic conditions, strategy (key words)

\section{INTRODUCTION}

The strategy of import of substitution is an analysis-driven exercise, where managers can succeed by sheer effort and creativity. Industry company's work with external environment and internal situations are associated geopolitical problems in the world. Unless a company's strategy import of substitution is well-matched to the full range of external and internal situational developments, its suitability is suspicious.

From a strategy-making standpoint, the purpose of situation analysis is to determine the features in a company's internal/external environment that most directly affect its strategic options and opportunities. The knowledge concentrates on generating solid well-defined set of strategic questions, then uses the answers first to form an understandable picture of the industrial company's strategic situation and second to identify what its realistic strategic options are.

\section{STRATEGIC SITUATION ANALYSIS}

In studying the methods of strategic situation analysis, it is customary to begin with single-business companies instead of diversified enterprises. This is because strategic analysis of diversified companies draws on many of the actions.

Concepts and techniques are used in evaluating the strategic situations of single-business companies. In single-business strategic analysis, the two biggest situational considerations are industry and competitive conditions (the heart of single-business industrial company's external environment) and the company's own internal situation and competitive position. This paper examines the techniques of industry and competitive analysis, the terms used to refer to external situation analysis of a single-business company. This paper covers the tools of company situation analysis. Industry and competitive analysis looks broadly at a company's macro-environment; company situation analysis examines the narrower field of its microenvironment. [1]

Fig. 1 presents the external-internal framework of strategic situation analysis for a single-business company. It indicates both the analytical steps involved and the connection to developing business strategy. It cover the strategy of import of substitution. Let us note the logical transition from analysis of the company's external and internal situation to evaluation of alternatives in the choice of the strategy. Also let us note that situation analysis is the starting point in the process. Indeed, as we shall see in the rest of this paper, managers must understand company's macro- and microenvironments to do a good job of establishing a mission, setting objectives, and crafting business strategy is good whether it fits the situation, or it helps build competitive advantage, or it is likely to boost company performance.

There are methods of industry and competitive analysis. Industries differ widely in their economic characteristics, competitive situations, and future outlooks. The pace of technological change can range from fast to slow. Capital requirements can be big or small. The market can be worldwide or local. Seller's products can be standardized or highly differentiated. Competitive forces can be strong or weak and can center on price, quality, service, or other variables. Buyer demand can be rising briskly or declining. Industry conditions differ so much that leading companies in unattractive industries can find it hard to earn respectable profits, while even weak companies in attractive industries can turn in good performances.[2]

Industry and competitive analysis utilizes a toolkit of concepts and techniques to get a clear fix on changing industry conditions and on the nature and strength of competitive forces. It is a way of thinking strategically about an industry's overall situation and drawing conclusions about whether the industry is an attractive investment for company funds. The framework for industry and competitive analysis hangs on developing probing answers to questions. Firstly, chief economic characteristics of 
the industry. Secondly, factors are driving change in the industry. Thirdly, competitive forces are at work in the industry.

Let us identify the Industry's Dominant Economic Characteristics. Since industries differ significantly in their basic character and structure, industry and competitive analysis begins with an overview of the industry's dominant economic traits. As a working definition, let us use the word industry to mean a group of firms whose products have so many of the same attributes that they compete for the same buyers. The factors to consider in profiling an industry's economic features are fairly standard:

- Market size.

- Scope of competitive rivalry (local, regional, national, or global).

- Market growth rate and where the industry is in the growth cycle (early development, rapid growth and takeoff, early maturity, late maturity and saturation, stagnant and aging, decline and decay).

- The number of buyers and their relative sizes.

- The prevalence of backward and forward integration.

- Ease of entry and exit.

- The pace of technological change in both production processes and new product introductions.

- Capital requirements.

- Whether industry profitability is above/below par.

Industry's economic characteristics are important because of the implications they have for strategy. For example, in capital-intensive industries, where investment in a single plant can run several hundred million dollars, a firm can ease the resulting burden of high fixed costs by pursuing a strategy that promotes high utilization of fixed assets and generates more revenue per dollar of fixed-asset investment. Thus commercial airlines employ strategies to boost the revenue productivity of their expensive jet aircraft fleets by cutting ground time at airport gates (to get in more flights per day with the same plane) and by discounting fares to fill up otherwise empty seats on each flight [3].

In industries characterized by one product advance after another, companies are driven to invest enough time and money in R\&D to keep their technical skills and innovative capability abreast of competitors. A strategy of continuous product innovation becomes a condition of survival.

In industries like semiconductors, the presence of a learning/experience curve manufacturing causes unit costs to decline by almost 20 percent each time the cumulative production volume doubles.

With a 20 percent, there is experience of curve effect, if the first 1 million chips cost $\$ 1$ each, by a production volume of 2 mln. The unit cost would be $\$ .80$ ( 80 percent of $\$ 1$ ); by a production volume of 4 million, the unit cost would be $\$ .64$ (80 percent of $\$ 0.80$ ); and so on. When an industry is characterized by a strong experience curve effect in its manufacturing operations, a company that moves first to initiate production of a new-style product and develops a strategy to capture the largest market share can win the competitive advantage of being the low-cost producer.
The bigger the experience curve effect, the bigger the cost advantage of the company with the largest cumulative production volume, as shown in Fig. 2 [4].

An industry's economic features say a lot about the basic nature of the industry environment, but very little about the ways in which the environment may be changing. All industries are characterized by trends and new developments that, either gradually or speedily, produce changes important enough to require a strategic response from participating firms.

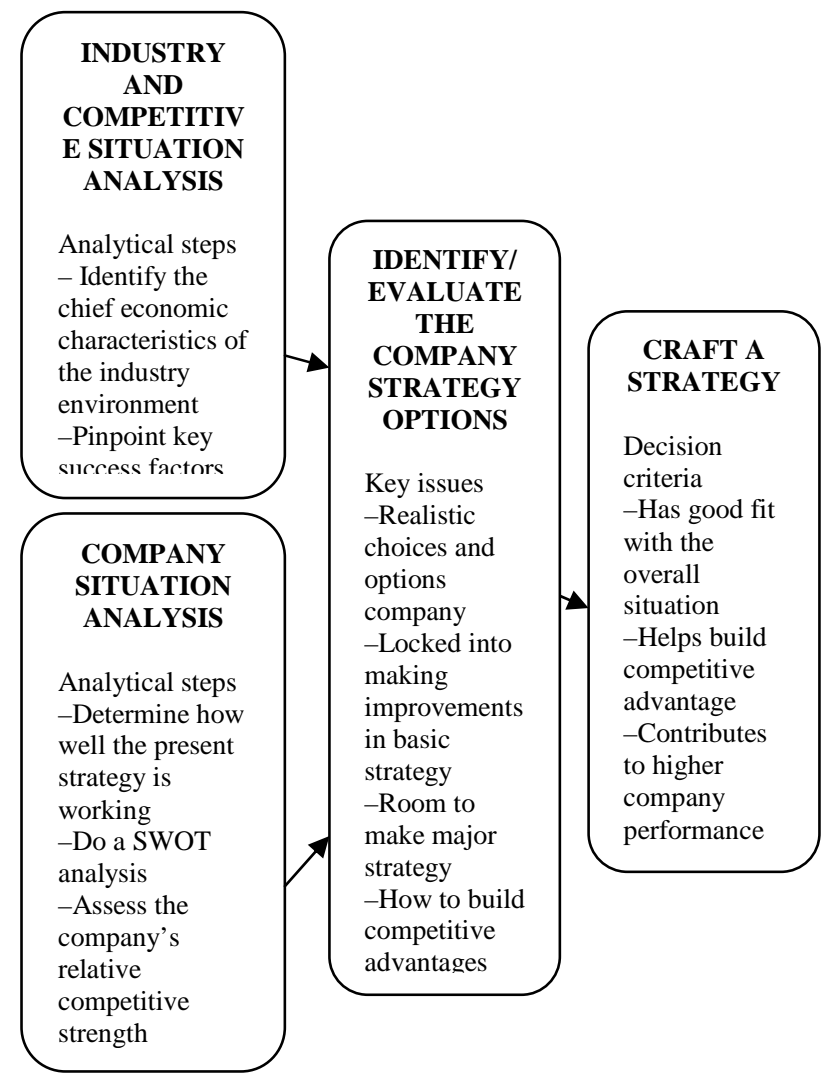

Fig. 1. Dominant economic characteristics

The popular hypothesis about industries going through evolutionary growth phases or life-cycle stages helps to explain why industry conditions change but it is still incomplete. The life-cycle stages are strongly keyed to the overall industry town rate which is why stages are described with such terms as rapid growth, early maturity, saturation, and decline). Yet there are more causes of industry and competitive change than moving to a new position on the growth curve.

While it is important to judge what growth stage an industry is there, there is more analytical value in identifying the specific factors causing industry change. Industry conditions change because forces are in motion that create incentives or pressures for change [5]. 


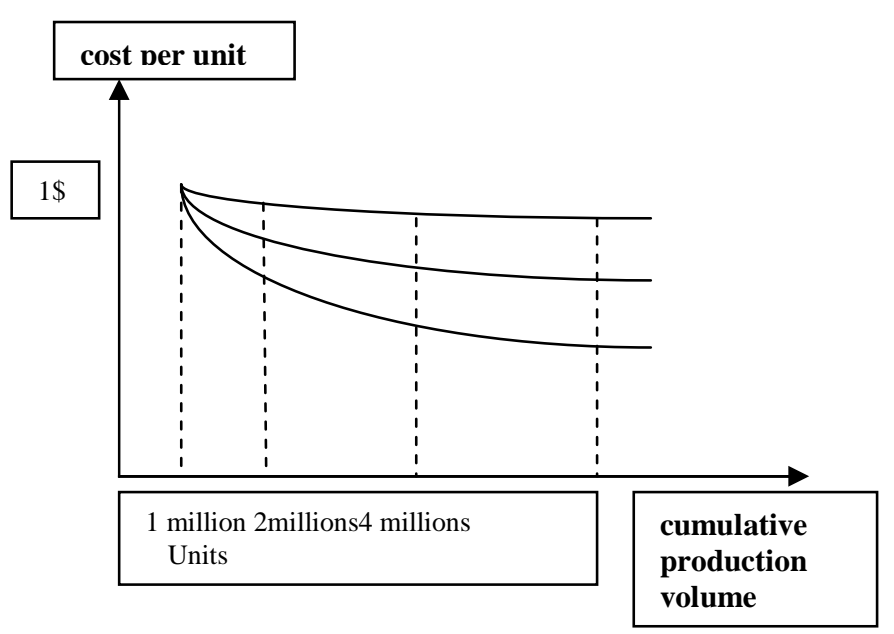

Fig. 2. Experience curve effect, the bigger the cost advantage of the company, the larger the cumulative production volume

\section{REALIZATION STRATEGY IMPORT OF SUBSTITUTION}

Many events affect an industry power-enough to qualify as driving forces. Some are of a kind, but most fall to several basic categories. The most common driving forces are shown here.

Changes in the Long-Term Industry Growth Rate. Shifts in industry growth up or down are a force for industry change because they affect the balance between industry supply and buyer demand, entry and exit, and how hard it will be for a firm to capture additional sales. A strong upsurge in long-term demand frequently attracts new firms and encourages established ones to invest in additional capacity. In a shrinking market, some firms will exit the industry, and the remaining ones may postpone further capacity investments [6].

It can also occur when the of technological know-how license others to use it for a fee or ream up with a company interested in turning the technology into a new business venture. Often companies acquire technical know-how by buying a company with the desired skills, patents, or manufacturing capabilities.

In recent years, technology transfer across national boundaries has emerged as one of the most important driving forces in globalizing markets and competition.

As companies in more countries gain access to technical know-how, they upgrade their manufacturing capabilities to compete with established companies. Technology transfer has turned many domestic industries into global ones (e.g., automobiles, tires, consumer electronics, telecommunications, and computers).

Increasing Globalization of the Industry. Global competition usually changes patterns of competitive advantage among key players. Industries move toward globalization for several reasons. Certain firms may launch aggressive long-term strategies to win a globally dominant market position. Demand for the industry's product may emerge in more countries. Trade barriers may drop. Technology-transfer may open the door for more companies in more countries to enter the industry on a major scale. Significant labor cost differences among countries may create a strong reason to locate plants for labor-intensive products in low-wage countries (wages in South Korea,
Taiwan, and Singapore, for example, are about one-fourth those in the United States). Significant cost economies may accrue to firms with world-scale volumes as opposed to national-scale volumes. The growing ability of multinational companies to transfer their production, marketing, and management know-how from country to country at significantly lower cost than companies with a one-country production base may give multinational competitors a significant competitive advantage over domestic-only competitors. Globalization is most likely to be a driving force in industries based on natural resources (supplies of crude oil, copper, and cotton, for example, are geographically scattered all over the globe), where low-cost production is a critical consideration (making it imperative to locate plant facilities in countries where the lowest costs can be achieved), and where one or more growth-oriented, market-seeking companies are pushing hard to gain a significant competitive position in as many attractive country markets as they can [7].

Changes in Cost and Efficiency. In industries where significant economies of scale are emerging or strong learning curve effects are allowing firms with the most production experience to undercut rivals' prices, large market share becomes such distinct advantage that all firms are pressured to adopt volume-building strategies a "race for growth" dominates the industry. Likewise, sharply rising costs for a key input (either raw materials or labor) can cause a scramble to either line up reliable supplies at affordable prices or search out lower-cost substitutes. Any time important changes in cost or efficiency take place; firms' positions can change radically concerning who has how big a cost advantage.

At the moment, the share of machine building accounts for $13.9 \%$ of the production of the industrial complex of Irkutsk region. The overwhelming majority of the products of these enterprises are exported to the regions of the European part of the country. From other areas of machine-building industry can be identified production of equipment for the mining industry, in particular for gold mining [8].

The structure of the machine-building complex of the Irkutsk region includes operating enterprises: IZTM, IRKUT, AKTEKH, VOSTSIBMASH, Irkutsk RELAY FACTORY, IR-KUTTSKKABEL, MZMK, BrAZMK, Cheremkhovsky MACHINE BUILDING PLANT, BRATSK HEATING SYSTEM FACTORY, ORE-REPAIR PLANT (VOSTSI-BOGOL), TIMOX, UZOLMASH , PLANT PPM-IRKUTSK, AEMZ, SIBMONTAZHAVTOMATIKA, IZEMI, SPO FACTORY, Irkutsk plant of low-voltage devices. 




Figure 3. Program realization of the strategy of import substitution illustrates the import-replacement strategy by the authors suggested by the example of Irkutsk region in industry machine-building.

Figure 3 shows a map of the locations of the above-mentioned enterprises. It is worth concluding that the greater part is concentrated in the southern part of the region. The research revealed that these companies have a huge industrial potential, as well as affordable trade routes. Therefore, it is necessary to introduce an import substitution strategy at the federal and regional levels [9].

\section{CALCULATION OF THE STRATEGY OF IMPORT SUBSTITUTION THROUGH THE PRODUCTION FUNCTION OF C.W.COBB, P.H.DOUGLAS}

The strategy is used for production function C.W. Cobb, P.H. Douglas. The production function determines the relationship between the costs of factors production and production in the production system. The production function describes the most effective production processes. All other less effective technological processes with free consumption of factors production are automatically excluded from consideration [10].

Production functions can be defined for production systems of different scales - from the production site to the world economy. Each production system is characterized by its own production function.

The apparatus of production functions is widely used in microeconomic and macroeconomic analysis in modeling production processes. With the help of production functions, one can assess the effectiveness of the system and the use of individual factors determining the opportunities and consequences of substitution factors of production by others, to find the influence of the scale of production on its effectiveness, to study the impact of managerial and technological innovations in production processes.[11]

Complexity of production systems leads to the fact that the production function can only be determined theoretically in the simplest cases. Finding a production function for a real production system represents a problem that is solved by statistical methods processing of empirical data.
1. Equation is defined in the general case products.

$F(x, y, a)=0$

Here $x=\left\{x_{1}, x_{2}, \ldots, x_{n}\right\}$-vector of resource factors, factor costs resources,

2. Vector of output of $m$ types of products

$y=\left\{y_{1}, y_{2}, \ldots, y_{n}\right\}$

3. Set of parameters.

$a=\left\{a_{1}, a_{2}, \ldots, a_{\mathrm{r}}\right\}$

Such entry defines implicitly defined functions.

Let us consider production functions of output of one kind products, that is, an explicitly defined function

4. Static production function.

$y=f\left(x_{1}, x_{2}, \ldots, x_{n}\right)$

5. Function C.W. Cobb, P.H. Douglas

$$
y=a x_{1}^{\alpha} \cdot x_{2}^{\beta}
$$

where $m=\alpha+\beta \geq 0$.

In this case, $f(\lambda x)=a\left(\lambda \mathrm{x}_{1}\right)^{\alpha} \cdot\left(\lambda \mathrm{x}_{2}\right)^{\beta}=a \cdot x_{1}^{\alpha} \cdot x_{2}^{\beta} \cdot \lambda^{\alpha+\beta}=$ $\lambda^{\mathrm{m}} f(x)$.

This, for the Cobb-Douglas function

$$
y=a x_{1}^{\alpha} \cdot x_{2}^{\beta}, m=\alpha+\beta .
$$

For the classical Cobb-Douglas function:

$$
m=1 \text {. }
$$

If $0 \leq m<1$, this means a decrease in output scale of production (decrease in output, curtailment, narrowing production).[12]

If $m=1$, then this means extensive production (neutral) with increasing scale of production.

If $m>1$, this means intensive production at increasing scale of production; greater increase in output at scale production.

Increasing the scale means that $x \rightarrow \lambda x, \lambda \geq 1$, for abstract reasoning $\lambda>1$.

6 . Let us consider the case: when $\lambda>1$ we see that

$f(\lambda x)=\lambda^{m} f(x)$, 
and $\lambda^{m}>\lambda, m>1$,i.ef $(\lambda x)>\lambda f(x)$

and $\lambda^{m}<\lambda, 0<m<1$,i.e $f(\lambda x)<\lambda f(x)$.

Numerical characteristics: marginal and average products, elasticity of output by factors

The performance of resources is estimated using indicators impact. In microeconomics, the notion of giving resources is specific. In that concept, on the one hand, there is the output of products (or its monetary expression: income, sales volume), on the other - the number of used resources (or payment for their acquisition) for a certain period of time. Resource performance indicators express economic efficiency from their introduction into production. They specify the general idea of relevant indicators [13]. used:

Resource efficiency indicators of three types are widely

- the average return on production resources,

- the maximum output of production resources,

- the elasticity of output by production resources.

All factors of factor productivity are calculated by changing only one resource. Let us introduce the mathematical formulas of these exponents and consider them in calculation in the case of a two-factor production function reflecting dependence of output on the vector of resources used. The average product (average return) of the resource is calculated by dividing the volume release by the amount of use of each resource. In the case of a two-factor PF apply the following formulas:

7. The average capital product:

$$
\lambda_{K}=y / K
$$

8. The average product of labor:

$$
\lambda_{L}=y / L
$$

Let us explain the meaning of the indicator of the average product of capital with the help of dependence of output $y$ on the use of capital $K$ under constant value of $L$ (Fig. 4).[14]

With the release of $y_{1}$, capital is used in the amount of $K_{1}$, the average product is equal to $y_{1} / K_{1}$. When issuing $y_{2}$, the capital used is $K_{2}$, and the average the product of capital is $y_{2} /$ $K_{2}$. Output and capital employed belong to the number of interval indicators.

Graphically, this index is equal to the tangent of the angle of inclination of the ray, passing through the origin and the point of determining the exponent $\left(K_{1}, y_{1}\right)$ or $\left(K_{2}, y_{2}\right)$, and so on. The period of time during which products are produced and use the resources, the same. Thus, the average product of capital determines the volume of output each unit of used capital over a period of time.

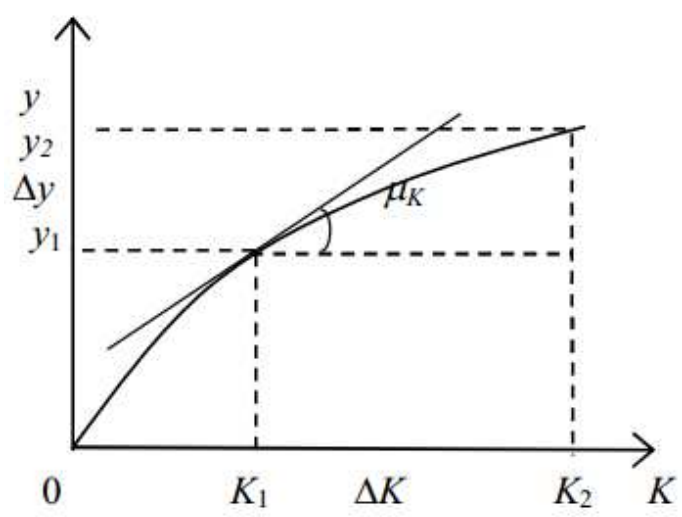

Fig. 4. Dependence of output y on the use of capital $K$ under constant value of $L$

Similarly, the index of the average product of labor is introduced, which expresses the volume of output per unit used labor. Thus, the average return (average product) of a resource is the quantity of output per unit of the corresponding resource, used in production.[15]

Using the mathematical formula of the PF Cobb-Douglas, these indicators can be calculated analytically. The average return on resources is determined by the following formulas.

9. The average product of capital

$$
\lambda_{K}=a K^{\alpha} L^{\beta} / K=a L^{\beta} / K^{1-\alpha}=a L^{\beta} / K^{\beta}=a(L / K)^{\beta}
$$

10. If one designates the ratio of used capital to labor costs by the letter $\varphi$, one will obtain the formula:

$$
\lambda_{K}=a(L / K)^{\beta}=a / \varphi^{\beta}
$$

11. The average product of labor has the form:

$\lambda_{L}=a K^{\alpha} L^{\beta} / L=a K^{\alpha} / L^{1-\beta}=a K^{\alpha} / L^{\alpha}=a(K / L)^{\alpha}=a \varphi^{\alpha}$

The marginal product (ultimate yield) of the resource is calculated by the formula of the partial derivative of the production function by factor production. For the two-factor $\mathrm{PF}$, the following formulas are used: [16]

12. The marginal product of capital:

$$
\mu_{K}=\partial y / \partial K
$$

13. The marginal product of labor:

$$
\mu_{K}=\partial y / \partial L
$$

Let us explain the meaning of the indicator of the marginal product of capital with the help of graphics (Fig. 4). Graphically, the marginal product of capital is equal to the 
tangent the angle of inclination of the tangent to the discharge line at the point of definition of the indicator [17].

If the dependence of the output on the factor is given discretely and the increase in output $\Delta y$ requires additional use of capital in quantity $\Delta K$, then the maximum return is calculated by the formula $\mu_{K}=\Delta y / \Delta K$. The limit of this relations with $\Delta K \rightarrow 0$ is the expression $\partial y / \partial K$. Similarly, the marginal product of labor [18].

Thus, the ultimate return of the resource is an increase output per unit increment of the corresponding resource, used in production.

With respect to the Cobb-Douglas PF, one can derive the following the formula for the maximum resource return:

14. The marginal product of capital:

$$
\mu_{K}=\partial y / \partial K=a \alpha K^{\alpha-1} L^{\beta}=a \alpha L^{\beta} / K^{\beta}=a \alpha / \varphi^{\beta}
$$

\section{The marginal product of labor:}

$$
\mu_{L}=\partial y / \partial L=a \beta K^{\alpha} L^{\beta-1}=a \beta K^{\alpha} / L^{\alpha}=a \beta \varphi^{\alpha}
$$

Let us consider the ratio of the average return on capital $\lambda_{K}=a / \varphi^{\beta}$ and the ultimate return on capital $\mu_{K}=$ $a \alpha / \varphi^{\beta}$. From these formulas it follows that $\mu_{K}=a \lambda_{K}$. At the same time, $0<\alpha<1$, consequently, $\mu_{K}<\lambda_{K}$. Similarly, from equations [19], it follow that:

$$
\begin{aligned}
& \mu_{L}=a \beta \varphi^{\alpha} \text { and } \lambda_{L}=a \varphi^{\alpha} \text { follows that } \\
& \mu_{L}=\beta \lambda_{L} .
\end{aligned}
$$

Given that $0<\beta<1$, let us obtain the relation $\mu_{L}<\lambda_{L}$.

In other words, in the Cobb-Douglas model, the marginal products of capital and labor are of lower importance than the average products of these resources production [20].

\section{DISCUSSION AND CONCLUSION}

In conclusion, the authors think that industry in country must be of high level since industry provides low level of unemployment, high incomes of the population, increase in the level of gross domestic product.

In Irkutsk region, it is necessary to create seed and seed funds that provide financial support to industrial operating enterprises. Sources of filling such funds can be funds that will be returned to the state when it leaves the previously created venture capital funds by selling its holdings of shares. The procedure for the formation and operation of such funds, especially with regard to the use of public resources, must be approved by a government decree [21].

Many people notice a number of shortcomings in the development of import substitution and the inability to completely overcome this milestone in large and small businesses. But if one plunges into the problem completely, then of course in the long run, on the order of decades, one can develop more fruitful mechanisms. This is strongly evident in the experience of the countries of Latin America and Norway, which show positive aspects and a really working economic system [22].

A lot of conclusions have been drawn and an enormous number of convictions have been ordered, on the basis of which it can be asserted that the presence of import substitution in the national economy of any country makes a huge contribution to economic growth and to the increase of the gross domestic product.

\section{Acknowledgment}

The authors acknowledge receiving support from state-funded research program of Irkutsk National Research Technical University. We are responsible for all errors as well as heavy style of the manuscript.

\section{References}

[1] A. Arhur, JR. Thompson, A.J. Strickland III., Strategy formulation and Implementation, Industry And Competition, $5^{\text {th }}$ ed., 2015, pp:448-460.

[2] Yu.N. Cheremnykh, Microeconomics Advanced level, The Faculty of Economics, MVLomonosov Moscow State University, Moscow, Chapter 6, 2008, pp. 36-89.

[3] M.V.Grachyova, L.N. Fadeeva, Yu..N..Cheremnykh, Modeling of economic processes, M.: UNITY-DANA, Chapter 3, pp. 10-68, 2005.

[4] S. S. Sinelnikov-Mourylev, The Russian Economy in Transition, Appendix "Modeling Tax Revenues and Taxes Liabilities of Russian Taxpayers in 1992 through 1998, MIT Press, 2013, pp. 25-38.

[5] G.M.Beregova, A.O.Klipin, "Investing in import substitution in the field of production(constructions materials)", Scientific journal IZVESTIYA VUZOV: Investitsii, Stroitelstvo, Nedvizhimost, vol. 2(17), 2016, pp. 19-24, March 2016.

[6] V.K. Bulgakov, V.V. Strigunov, "About optimal control and optimal trajectories dynamics of regional macroeconomics based on the maximum principle Pontryagin", Journal of Computing mathematics and mathematical physics, No. 5, pp: 776-790, April 2009.

[7] S.E. Batishchev, E.D. Kadaner, P.M. Simonov, "Mathematical Models of Microeconomics", Perm scientific journal, 2 nd ed, pp: 20-78, September 2006

[8] A.F. Grishin, S.F. Kotov-Darty, V.N. Yagunov, Statistical Models in Economics: Proc. Allowance, Rostov n / a: "Phoenix" Ser. "High form", Chapter 4, pp. 34-65, 2005.

[9] A.V. Panyukov, Mathematical modeling of economic processes, Moscow: Prince. house "LIBROKOM", Chapter 4, pp. 15-36, 2010.

[10] S.I. Shelobayev, Economic-mathematical methods and models, Proc.manual for universities, 2 nd ed. Chapter 1, pp. 11-36, 2005.

[11] V.V. Shulikovskaya, "Mathematical Economics", SRC "Regular and chaotic dynamics", In-t computer.Issled, pp. 96-120, March 2006.

[12] I.N. Drogobytsky, "Economic and Mathematical Modeling", Textbook for Studentsuniversities / Under the general. Ed, Chapter 7, pp. 52-78, 2004.

[13] P.A.Kadochnikov, An Analysis of Import Subsritution in Russia after the 1998 Crysis, Science paper Institute for the economy in transition, Vol. 95, pp. 39-59,2006.

[14] Keith Crane, Andreas Goldthau, Michael Toman, Imported oil and U.S. national security: monograph,Santa Monica: Rand corporation, 2009, pp. 127-145.

[15] J. Hawk, Victory of import substitution: Russia begins to export meat to the EU, 2015, URL: http://www.fort-russ.com/2015/03/victory-for-import-substitution-russia. html

[16] P. Giordano, K. Michalczewsky, A. Ramos, "Latin American trade trend estimates", Inter-American Development, pp. 18-29, 2015.

[17] Yu Zhou, "Synchronizing Export Orientation with Import Substitution: Creating Competitive Indigenous High-Tech Companies in China", World Development, Vol. 36, Issue 11, pp. 2353-2370, November 2008.

[18] M. Rodrigues, "Import substitution and economic growth", Journal of Monetary Economics, Vol. 57, Issue 2, pp. 175-188, March 2010.

[19] Carlos Andrés Brando "Winners and losers in the allocation of credit during the era of import-substitution industrialisation in Colombia", 1940-1967, Ensayos sobre Política Económica, Vol. 34, Issue 79, pp. 21-39, April 2016. 
[20] A. Savelyev, "Legal aspects of ownership in modified open source software and its impact on Russian software import substitution policy", Computer Law \& Security Review, Vol. 33, Issue 2, pp. 193-210, April 2017.

[21] Aregbeshola R.Adewale, "Import substitution industrialisation and economic growth - Evidence from the group of BRICS countries", Future Business Journal, Vol. 3, Issue 2, pp. 138-158, December 2017.

[22] I. Ershova, A. Ershov, "Development of a Strategy of Import Substitution", Procedia Economics and Finance, Vol. 39, pp. 620-624, 2016. 